\title{
One process for pancreatic $\beta$-cell coalescence into islets involves an epithelial-mesenchymal transition
}

\author{
Lori Cole ${ }^{1}$, Miranda Anderson', Parker B Antin ${ }^{2}$ and Sean W Limesand \\ ${ }^{1}$ Department of Animal Sciences, Agricultural Research Complex and ${ }^{2}$ Department of Cell Biology and Anatomy, University of Arizona, 1650 East Limberlost \\ Drive, Tucson, Arizona 85719, USA \\ (Correspondence should be addressed to S W Limesand; Email: limesand@ag.arizona.edu)
}

\begin{abstract}
Islet replacement is a promising therapy for treating diabetes mellitus, but the supply of donor tissue for transplantation is limited. To overcome this limitation, endocrine tissue can be expanded, but this requires an understanding of normal developmental processes that regulate islet formation. In this study, we compare pancreas development in sheep and human, and provide evidence that an epithelial-mesenchymal transition (EMT) is involved in $\beta$-cell differentiation and islet formation. Transcription factors know to regulate pancreas formation, pancreatic duodenal homeobox factor 1 , neurogenin 3 , NKX2-2, and NKX6-1, which were expressed in the appropriate spatial and temporal pattern to coordinate pancreatic bud outgrowth and direct endocrine cell specification in sheep. Immunofluorescence staining of the developing pancreas was used to co-localize insulin and epithelial
\end{abstract}

proteins (cytokeratin, E-cadherin, and $\beta$-catenin) or insulin and a mesenchymal protein (vimentin). In sheep, individual $\beta$-cells become insulin-positive in the progenitor epithelium, then lose epithelial characteristics, and migrate out of the epithelial layer to form islets. As $\beta$-cells exit the epithelial progenitor cell layer, they acquire mesenchymal characteristics, shown by their acquisition of vimentin. In situ hybridization expression analysis of the SNAIL family members of transcriptional repressors (SNAIL1, -2, and -3; listed as SNAI1, -2, -3 in the HUGO Database) showed that each of the SNAIL genes was expressed in the ductal epithelium during development, and SNAIL-1 and -2 were co-expressed with insulin. Our findings provide strong evidence that the movement of $\beta$-cells from the pancreatic ductal epithelium involves an EMT.

Journal of Endocrinology (2009) 203, 19-31

\section{Introduction}

A central therapeutic goal for treating diabetic patients is to restore adequate $\beta$-cell function; however, the quantity of donor tissue for islet transplantation is inadequate (Shapiro et al. 2000, Grapin-Botton 2005, Nir \& Dor 2005). To combat this limitation a renewable source of $\beta$-cells is required, and a possible solution includes in vitro $\beta$-cell production. A prerequisite for expanding $\beta$-cells in vitro is to understand the normal developmental processes involved in islet formation. Although some recent reports indicate that endocrine cytodifferentiation in the human pancreas is similar to that of the mouse, detailed analyses have revealed important differences between human and mouse with respect to the timing of $\beta$-cell differentiation (Piper et al. 2004, Sarkar et al. 2008). Therefore, to better understand pancreatic morphogenesis in humans, who have longer pregnancy than rodents, comparative animal systems will be needed. The sheep is a long standing large animal model for studying fetal physiology, and we have observed that the progression of pancreas development in the fetal sheep closely parallels the progression observed in human. This has allowed us to monitor the multi foci differentiation pattern to examine islet formation in a species with a longer gestation period (Limesand et al. 2005, Cole et al. 2007).

It is generally accepted that islets originate from epithelial progenitor cells because emerging endocrine cells transiently retain epithelial characteristics and are usually located close to or within the pancreatic duct epithelium (Slack 1995, Bonner-Weir et al. 2000, Yatoh et al. 2007). The mechanism for how pancreatic islets arise from this epithelial cell layer remains unresolved, but appears to involve two distinct processes. In the rat, the most prominent mechanism for islet morphogenesis involves the formation of large ductal cell aggregates, termed islet-forming units, the cells of which begin expressing insulin and other endocrine hormones, while still associated with the epithelium (Bouwens \& De 1996). These aggregates gradually lose contact with the epithelium and ultimately form morphologically recognizable islets. In the human, groupings of polyhormonal expressing cells are also observed connected to pancreatic ducts (Bocian-Sobkowska et al. 1999), which supports this isletforming unit theory. Such a mechanism might explain a role for lateral communication in coordinating the differentiation and formation of islet structures. 
A second mechanism of islet cell development was suggested by the work of Pictet \& Rutter (1972), which showed that individual endocrine cells first appear within the ductal epithelium, then leave the epithelial layer, and coalesce to form islets of Langerhans. A similar process has been described in the mouse (Jensen 2004), where it was postulated that after the secondary transition individual endocrine cells leave the ductal epithelium and migrate to form aggregates. In both human (Piper et al. 2004, Sarkar et al. 2008) and sheep (Limesand et al. 2005), individual endocrine cells are observed within and adjacent to the duct throughout gestation indicating a common mechanism for the origin of at least some endocrine cells. Although the general changes in cell morphology that occur during this single cell migration (or 'budding') suggest that an epithelial-mesenchymal transition (EMT) is involved, the process has not been carefully defined in any species.

EMT is an important developmental process by which migratory mesenchymal cells arise from an epithelium, ultimately forming new structures in many embryonic tissues (Kang \& Massague 2004, Radisky 2005). There is evidence to support an EMT as a plausible mechanism for the origin of pancreatic endocrine cells. In a single-cell transcript analysis during mouse pancreas development, all neurogenin 3 (Ngn3) expressing cells co-expressed the epithelial cell marker E-cadherin, and a majority also expressed the mesenchymal cell marker vimentin (Chiang \& Melton 2003). Furthermore, approximately a quarter of the insulin ${ }^{+}$cells co-expressed vimentin and the epithelial cell marker cytokeratin. These findings indicate that endocrine progenitor cells typically express both epithelial and mesenchymal cell markers, indicating a transitory period between epithelial and mesenchymal phenotypes. In addition to the expression of Snail-2, a transcriptional repressor that mediates an EMT, is present in the endocrine progenitor cells and differentiated $\beta$-cells during mouse pancreas development (Rukstalis \& Habener 2007). Finally, an EMT was also shown to promote expansion of human islet cells and nonendocrine epithelial cells in vitro by $\beta$-cell dedifferentiation to a mesenchymal phenotype, which in some circumstance could be reversed to produce a population of insulin ${ }^{+}$cells (Gershengorn et al. 2004, Ouziel-Yahalom et al. 2006, Seeberger et al. 2009). This dedifferentiation phenomenon was not observed in adult islets from rodent and most likely reflects species differences that are further supported by our studies in sheep (Russ et al. 2008).

Together, these findings provide support to the idea that an EMT is associated with $\beta$-cell differentiation, but as of yet this process has not been defined in any species. Here we compare the origin of pancreatic endocrine cells in the developing human and sheep. We find that the timing and mechanisms of origin of $\beta$-cells in the sheep and human are highly similar. In both human and sheep, we identify two processes for islet formation; the so called islet-forming unit in which large aggregates of ductal epithelial cells become insulin-positive and bud off from the duct as one unit, and a single cell process in which individual insulin-positive cells emerge from the ductal epithelium. Immunofluorescence and in situ hybridization analyses provide strong evidence that this latter process involves an EMT.

\section{Materials and Methods}

\section{Pancreatic collection and processing}

Pancreata were dissected from sheep fetuses and fixed in 4\% paraformaldehyde (PFA) in PBS $(137 \mathrm{mM} \mathrm{NaCl}, 2 \cdot 7 \mathrm{mM}$ $\left.\mathrm{KCl}, 4 \cdot 3 \mathrm{mM} \mathrm{Na}_{2} \mathrm{HPO}_{4} \cdot \mathrm{H}_{2} \mathrm{O}, 1 \cdot 4 \mathrm{mM} \mathrm{KH}_{2} \mathrm{PO}_{4}, \mathrm{pH} 7 \cdot 3\right)$ at $4{ }^{\circ} \mathrm{C}$ for $14-24 \mathrm{~h}$. The tissues were immersed in $30 \%$ sucrose overnight at $4{ }^{\circ} \mathrm{C}$ and then equilibrated in a $1: 130 \%$ sucrose: optimal cutting temperature (OCT) compound (volume:volume) mixture for an additional $24 \mathrm{~h}$ at $4{ }^{\circ} \mathrm{C}$. Tissues were embedded with OCT (Tissue Tek manufactured for Sakura Finetek USA, Inc., Torrance, CA, USA), frozen, and stored at $-80^{\circ} \mathrm{C}$. Six micrometres thick tissue sections were cut with a cryostat (Microm HM 520) for immunostaining and in situ hybridization procedures. Human pancreas tissue sections were collected by Prof. John C Hutton and Dr Suparna Sarkar, Barbara Davis Center for Childhood Diabetes (UCDHSC, Aurora, CO, USA), and fetal mouse sections were collected by Dr Lori Sussel, Department of Genetics and Development (University of Columbia, New York, NY, USA).

\section{Immunofluorescent staining}

Pancreas sections were dried to Superfrost Plus slides for $30 \mathrm{~min}$ at $37^{\circ} \mathrm{C}$ and then washed twice with water for $5 \mathrm{~min}$. Antigen retrieval was performed by microwaving tissues in $10 \mathrm{mM}$ citric acid buffer, $\mathrm{pH} 6 \cdot 0$ for $10 \mathrm{~min}$. The tissues were cooled for $20 \mathrm{~min}$, washed three times in PBS for $5 \mathrm{~min}$, and non-specific binding sites were blocked with $0 \cdot 5 \%$ NEN blocking buffer reagent $(0 \cdot 1 \mathrm{M}$ Tris- $\mathrm{HCl}, 0.15 \mathrm{M} \mathrm{NaCl}$; Perkin-Elmer) for $45 \mathrm{~min}$. Primary antiserum was diluted in $1 \%$ BSA supplemented PBS, applied to the section, and incubated at $4{ }^{\circ} \mathrm{C}$ overnight in a humidified chamber; exclusion of primary antiserum served as the negative control.

Pancreatic $\beta$-cells were identified in the fetal sheep pancreas with guinea pig anti-porcine insulin (1:500; Dako, Carpinteria, CA, USA), mouse anti-sheep insulin C-peptide (1:500; S W Limesand), rabbit anti-mouse pancreatic duodenal homeobox factor 1 (Pdx1; 1:1000; Millipore, Billerica, MA, USA), and rabbit anti-mouse Nkx6.1 (1:500; J Jensen, Cleveland, OH, USA). Epithelial cells were identified in the fetal sheep pancreas with mouse antihuman pan-cytokeratins 4, 5, 6, 8, 10, 13, 18 (1:250; Research Diagnostic, Inc., Concord, MA, USA), rabbit anti$\beta$-catenin (1:100; Lab Vision Neomarkers, Fremont, CA, USA), and guinea pig anti-E-cadherin (1:100; J C Hutton). Mesenchymal cells were identified with mouse anti-vimentin IgM (1:11 000; Sigma-Aldrich). Antibody specificity for epithelial and mesenchymal proteins was verified by immunoblot analysis, and all antiserum-detected proteins 
of appropriate molecular weight in fetal sheep pancreas. After incubation with the primary antiserum, the tissue sections were washed three times for $10 \mathrm{~min}$ with PBS. Immunocomplexes were detected with affinity-purified secondary antiserum conjugated to Cy2, Cy3, Texas Red, or 7-amino-4-methylcoumarin-3-acetic acid (Jackson ImmunoResearch Laboratories, West Grove, PA, USA) diluted 1:500 in $1 \%$ BSA-PBS for $60 \mathrm{~min}$ at $25^{\circ} \mathrm{C}$. The tissues were then washed with PBS $(3 \times$ for $10 \mathrm{~min})$ and mounted in $50 \%$ glycerol with $10 \mathrm{mM}$ Tris- $\mathrm{HCl}, \mathrm{pH} 8$.

\section{Chromogen immunohistochemistry}

Pancreas sections were washed twice with distilled water for $5 \mathrm{~min}$. Endogenous peroxidases were quenched in $0 \cdot 3 \%$ $\mathrm{H}_{2} \mathrm{O}_{2}$ in water during two 10-min incubations. The Vectastain Elite ABC Kits (Vector Laboratories, Burlingame, CA, USA) were used for immunostaining, as per the manufacturer's instructions, and detected with $3,3^{\prime}$-diaminobenzidine (DAB) peroxidase substrate (Vector Laboratories). Tissues were rinsed in water and dehydrated through a series of increasing ethanol washes, cleared with Histo-clear, and mounted with Securemount (Thermo Fisher Scientific, Waltham, MA, USA).

\section{Morphometric analysis}

Fluorescent images were visualized on a Leica DM5500 Microscope System and digitally captured with a Spot Pursuit 4 Megapixel CCD camera (Diagnostic Instruments, Inc., Sterling Heights, MI, USA). Confocal fluorescent images $(0 \cdot 7 \mu \mathrm{m}$ thick) were captured on a Zeiss LSM 510NLO-Meta Multiphoton/Confocal Microscope System (Carl Zeiss, Inc., Thornwood, NY, USA). Morphometric analysis was performed with Image Pro Plus 5.1 software (Media Cybernetics, Silver Spring, MD, USA). To determine the percentage of $\beta$-cells expressing vimentin, 300-1400 $\beta$-cells were counted per pancreas ( $n \geq 3 /$ gestational age group). The human data set consisted of ten individuals, four adults, and six fetal subjects (ranging from 11 to 23 weeks gestational age (wGA) previously reported (Sarkar et al. 2008). Five adult rat pancreata from two strains, Sprague-Dawley (8 months old, $n=3$ ), or Fisher (5 months old, $n=2$ ) were examined alongside seven pancreata of $\mathrm{FVB} / \mathrm{N}$ mice at 4 weeks of age. All values are presented as mean \pm s.E.M.

\section{In situ hybridization}

Ovine SNAIL1 (SNAI1), SNAIL2 (SNAI2), SNAIL3 (SNAI3), NGN3 (NEUROG3), and NKX2-2 DNA products were amplified from total RNA extracted from fetal sheep pancreas by reverse transcription-PCR. Synthetic oligonucleotide primers were designed from the bovine sequences: SNAIL1, 5'-CGA CAC TCA TCT GGG ACT CTC- $3^{\prime}$ and $5^{\prime}$-ACC CAG GCT GAT GTA CTC CTT-3'; SNAIL2, 5'-CCT GGT CAA GAA GCA TTT CAA- $3^{\prime}$ and
5'-CAG GCT CAC GTA TTC CTT GTC-3'; SNAIL3, $5^{\prime}$-TCA GAG ACA GCG TGA ACC AC- $3^{\prime}$ and $5^{\prime}$-TGC CGT ACT CCT TGT CAC AG-3'; NGN3, $5^{\prime}$-AAG GAT GRC GCC TCA WCC CT- $3^{\prime}$ and $5^{\prime}$-ATG TAG TTG TGG GCG AAG C-3' (nest PCR with $5^{\prime}$-AAG GAT GRC GCC TCA WCC CT- $3^{\prime}$ and $5^{\prime}$-TTT CAC AGR AAR TCT GAG A- $3^{\prime}$ in first reaction); and Nkx2.2, ${ }^{\prime}$-ATG TCG CTG ACC AAC ACA AAG A-3 ${ }^{\prime}$ and $5^{\prime}$-TGT ACT GGG CGT TGT ACT GC- $3^{\prime}$. The DNA products were cloned and sequenced as previously described (Limesand et al. 2007). All nucleotide sequences were submitted to GenBank: SNAIL1, EU081875; SNAIL2, EU081876; SNAIL3, EU081877; NGN3, DQ072379; and NKX2-2, DQ054804.

Plasmid DNA, linearized using the appropriate restriction endonuclease enzyme, was extracted with phenol:chloroform:isoAmyl (25:24:1), chloroform:isoAmyl (24:1), precipitated in ethanol with ammonium acetate, washed with 70\% ethanol, and dried. The linear DNA was re-suspended in nuclease-free water, and the integrity and concentration were measured by agarose gel electrophoresis and spectrophotometry with a Nanodrop Spectrophotometer ND-100 (Thermo Fisher Scientific). The digoxigenin (DIG)-labeled RNA probe was generated with SP6 or T7 RNA polymerase (Promega) with the reaction containing $1 \mu \mathrm{g}$ linearized DNA in $1 \times \mathrm{txn}$ buffer, $2 \mathrm{ng} / \mu \mathrm{l}$ DIG labeling mix (Roche), $0.5 \mathrm{U} / \mu \mathrm{l}$ RNAsin, $1 \mathrm{mmol} / 1$ dithiothreitol, and $1 \mathrm{U} / \mu \mathrm{l} 7$ or $0.7 \mathrm{U} / \mu \mathrm{l}$ SP6 RNA polymerase (Promega) at a final volume of $20 \mu \mathrm{l}$. The reaction was incubated for $>3 \mathrm{~h}$ at $37^{\circ} \mathrm{C}$. The DIG-labeled RNA probe was ethanol precipitated with ammonium acetate and $0 \cdot 2 \mu \mathrm{g}$ glycogen. The RNA pellet was washed with $70 \%$ ethanol, dried, and re-suspended in $100 \mu \mathrm{l}$ sterile water. RNA concentrations were determined by measuring the absorbance at A260, and DIG-labeled RNA integrity was assessed on an agarose gel.

Pancreas sections were fixed in fresh 4\% PFA in PBS for $10 \mathrm{~min}$, washed three times in PBS for $3 \mathrm{~min}$, digested with $10 \mu \mathrm{g} / \mathrm{ml}$ proteinase $\mathrm{K}(50 \mathrm{mmol} / 1$ Tris, $\mathrm{pH} 7 \cdot 5,5 \mathrm{mmol} / 1$ EDTA) for 8 min, and fixed again in fresh 4\% PFA in PBS for $5 \mathrm{~min}$. After three $3 \mathrm{~min} 1 \times \mathrm{PBS}$ washes, pancreatic tissue sections were acetylated $(102 \mathrm{mmol} / \mathrm{l}$ triethanolamine, $0.01 \mathrm{mmol} / \mathrm{l} \mathrm{HCl}, 27 \mathrm{mmol} / \mathrm{l}$ acetic anhydride) for $10 \mathrm{~min}$ at room temperature and washed thrice in PBS for $5 \mathrm{~min}$. Nonspecific binding was blocked by incubating the tissues in hybridization buffer $(50 \%$ formamide, $5 \times \mathrm{SSC} \mathrm{pH} 4 \cdot 5$, $50 \mu \mathrm{g} / \mathrm{ml}$ yeast tRNA, $1 \%$ SDS, $50 \mu \mathrm{g} / \mathrm{ml}$ heparin) for $2 \mathrm{~h}$ at $55{ }^{\circ} \mathrm{C}$. The DIG-labeled RNA was added to the hybridization buffer (snail-1: anti-sense $110 \mathrm{ng} / \mu \mathrm{l}$, sense $78 \mathrm{ng} / \mu \mathrm{l}$; snail-2: anti-sense $98 \mathrm{ng} / \mu \mathrm{l}$, sense $115 \mathrm{ng} / \mu \mathrm{l}$; snail-3: anti-sense $83.6 \mathrm{ng} / \mu \mathrm{l}$, sense $38.6 \mathrm{ng} / \mu \mathrm{l}$ ), heatdenatured at $80{ }^{\circ} \mathrm{C}$ for $5 \mathrm{~min}$, cooled for $5 \mathrm{~min}$, and applied to the tissue, which was then covered with a glass cover slip and incubated overnight at $70{ }^{\circ} \mathrm{C}$ in a humidified chamber. Cover slips were removed and pancreas sections were washed in pre-warmed, $70^{\circ} \mathrm{C} 5 \times \mathrm{SSC}(1 \times \mathrm{SSC}: 150 \mathrm{mmol} / \mathrm{l} \mathrm{NaCl}$, $15 \mathrm{mmol} / 1$ sodium citrate, $\mathrm{pH}$ to $7 \cdot 0$ ) for $30 \mathrm{~min}$ at room temperature, then incubated in pre-warmed, $70{ }^{\circ} \mathrm{C}$ 
$0 \cdot 2 \times \mathrm{SSC}$ for $3 \mathrm{~h}$ at $70{ }^{\circ} \mathrm{C}$. The tissues were washed at room temperature in $0 \cdot 2 \times \mathrm{SSC}$ for $5 \mathrm{~min}$, then equilibrated in Malic acid buffer $(1 \times \mathrm{MAB} ; 100 \mathrm{mmol} / 1$ maleic acid, $150 \mathrm{mmol} / \mathrm{l} \mathrm{NaCl}, \mathrm{pH} 8 \cdot 0$ ) for $5 \mathrm{~min}$. Pancreas sections were incubated in blocking buffer ( $2 \%$ blocking reagent (Roche Applied Science), $10 \%$ heat inactivated sheep serum, $0 \cdot 1 \%$ Tween-20 and brought to a final volume with $1 \times \mathrm{MAB}$ ) for $1 \mathrm{~h}$ at room temperature, and then incubated overnight at $4{ }^{\circ} \mathrm{C}$ in blocking buffer containing anti-DIG-AP Fab fragments antibody (Roche Applied Science; 1:1000). Following the incubation, the pancreatic sections were washed for $15 \mathrm{~min}$ three times with $\mathrm{MAB}$ containing $0 \cdot 1 \%$ Tween-20, and then washed in distilled water with $0 \cdot 1 \%$ Tween-20 for $20 \mathrm{~min}$. Pancreas sections were developed in BM Purple AP Substrate (Roche Applied Science) supplemented with $0 \cdot 1 \%$ Tween-20 for 3-36 h.

\section{Results}

\section{Conserved processes for endocrine lineage specification in sheep}

From the mouse, a hierarchy of transcription factors involved in endocrine cell determination from pluripotent pancreatic progenitors has been established (Jensen 2004). Using this knowledge, we determined PDX1, NGN3, and Nkx homeobox proteins, NKX2.2 and NKX6.1, expression in sheep.

At 24 days gestational age (dGA; 0.16 of gestation), the dorsal pancreatic bud was organized as a dense outgrowth (Fig. 1A). Robust PDX1 staining was detected in a majority of the epithelial cell nuclei of the pancreatic bud and antral stomach. After elongation into the surrounding mesenchymal tissue, occurring between 24 and $29 \mathrm{dGA}$ in the sheep, the strong PDX1 nuclear staining became restricted to $\beta$-cells (insulin ${ }^{+}$), but less intense nuclear staining and diffuse cytoplasmic staining was still present in the pancreatic endoderm at $33 \mathrm{dGA}(0 \cdot 22$ of gestation; Fig. 1B). By $131 \mathrm{dGA}(0.9$ of gestation), the PDX1 staining was predominantly localized to cells expressing insulin in either $\beta$-cell clusters or individual $\beta$-cells (Fig. 1C).

In the mouse, Ngn3 is required for endocrine cell determination committing pancreatic epithelial progenitor cells to an endocrine fate (Gradwohl et al. 2000). We cloned the ovine NGN3 gene, which shares $83 \%$ identity with human, to perform in situ hybridizations on sheep pancreas. Anti-sense NGN3 was expressed in either solitary cells or grouped into small clusters in the pancreatic epithelium at 24 dGA, 63 dGA, and lambs at postnatal day 10 (Fig. 1D). No specific staining was found with the DIG-labeled sense strand of NGN3 (Fig. 1D, insert). Similar to the mouse and human, the $\mathrm{Ngn}^{+}$cells do not co-express mature endocrine hormones, insulin or glucagon, further substantiating its role as an islet cell precursor in sheep (Fig. 1E and F; Jensen et al. 2000, Sarkar et al. 2008). To validate NGN3's temporal expression in pre-endocrine cells, we also evaluated NKX2.2 expression in sheep. In the mouse, $N k \times 2.2$ is expressed downstream of $N g n 3$ in the sequence of transcription factors that determine endocrine cell differentiation from pancreatic progenitors (Sussel et al. 1998). The nucleotide sequence for ovine NKX2.2 shared $94 \%$ identity with human NKX2.2. In sheep, the expression pattern of NKX2.2 appears to overlap NGN3, but was more extensive because NKX2.2 expression persists in both insulin ${ }^{+}$cells and most glucagon ${ }^{+}$cells (Fig. $1 \mathrm{G}$ and $\mathrm{H}$ ). Another transcription factor downstream of NKX2.2 in the lineage of $\beta$-cell specification is NKX6.1 (Sander et al. 2000) and in the sheep pancreas, we found that NKX6.1 was predominantly localized to insulin ${ }^{+}$cells, but occasionally NKX6.1 ${ }^{+}$insulin $^{-}$cells were observed (Fig. 2Q-T). Strikingly, even though the secondary transition (e.g. endocrine cell differentiation) was extended in the sheep, similar to the human (Piper et al. 2004, Sarkar et al. 2008), the progression through the previously defined cascade of critical transcription factors was conserved.

Two processes for islet formation in the sheep and human pancreas

Fetal sheep and human pancreata were immunostained for insulin, vimentin, and $\beta$-catenin to identify $\beta$-cells, mesenchymal cells, and epithelial cells respectively. In fetal sheep, $\beta$-cells were observed in three distinct morphological structures: the ductal epithelium, the mesenchymal stroma, and endocrine cell clusters (Fig. 3). Solitary $\beta$-cells were found in and immediately adjacent to the ductal epithelium and in the mesenchymal stroma at all gestational ages examined (29-142 dGA). $\beta$-Cell clusters were also present in the pancreatic parenchyma at all gestational ages examined. Some clusters were closely associated with the ductal epithelium and likely represent the islet-forming units previously described (Bocian-Sobkowska et al. 1999). Other $\beta$-cell clusters appeared as isolated structures, likely representing coalescing islets. These $\beta$-cell morphologies were also observed in the human fetal pancreas at 11 and 23 wGA $(0 \cdot 28$ and 0.55 of gestation; Fig. 3D-G). Individual $\beta$-cells and $\beta$-cell clusters were identified in both the mesenchymal and epithelial compartments of the developing pancreas.

These findings suggest that in both sheep and humans, $\beta$-cell clusters arise through two independent processes; as individual cells that move from the ductal epithelium to the stroma, and as large aggregates of cells that emerge within the ductal epithelium and then bud off to form isolated clusters.

\section{$\beta$-Cells differentiate from pancreatic ducts and lose epithelial characteristics}

Fetal sheep pancreata were immunostained for insulin, PDX1, and cytokeratin proteins to demarcate $\beta$-cells (insulin ${ }^{+}$and $\mathrm{PDX}^{+}$) and epithelial cells $\left(\right.$cytokeratin $\left.{ }^{+}\right)$. Individual $\beta$-cells within the ductal epithelium and immediately adjacent to the lumen typically showed distinct cytokeratin staining along the plasma membrane (Fig. 2A-D). Single $\beta$-cells that were not adjacent to the lumen of the pancreatic ducts but located within the ductal 



Figure 1 Developmental progression of transcriptional regulatory factors in sheep. Immunofluorescent staining for PDX1 (Cy2, green) and insulin (Texas Red) was determined in the sheep pancreas at several stages of gestation (A-C). A longitudinal cross section at $24 \mathrm{dGA}$ of the dorsal pancreatic bud and stomach (s) are shown (A), and the arrow identifies a $\mathrm{PDX}^{+}{ }^{+}$insulin $^{+}$cell. At $33 \mathrm{dGA}$ elongated ducts composed of PDX $1^{+}$epithelium were surrounded by a mesenchymal bed (B), solitary insulin ${ }^{+}$cells with nuclear PDX1 staining are apparent, whereas insulin ${ }^{-}$cells exhibit a variety of PDX1 staining localized in the nucleus and/or cytoplasm. Both mature islet-like structures and solitary insulin ${ }^{+}$cells (arrow) are shown at $131 \mathrm{dGA}(\mathrm{C})$, and E-cadherin staining in blue is observed in the epithelium. Representative photographs of sheep pancreas with differential interference contrast microscopy are shown for in situ hybridization with antisense or sense (insert) DIG-labeled neurogenin 3 RNA for fetuses at 24 and 63 dGA, and a lamb at postnatal day 10 (D).

The black arrows identify examples of $\mathrm{NGN} 3^{+}$cells stained with BM purple. The inserted picture illustrates the negative control, NGN3 sense strand (s), for the $63 \mathrm{dGA}$ fetus and encompasses an area equivalent to the area of the antisense picture. A $63 \mathrm{dGA}$, sheep pancreatic section was stained for NGN3 by in situ hybridization techniques and subsequently immunostained for insulin (E) or glucagon (F). Pancreas section from a sheep fetus at $33 \mathrm{dGA}$ was stained for NKX2.2 using in situ hybridization methodologies and then immunostained for insulin $(G)$ or glucagon $(H)$. In all photographs, the factors are labeled above in their respective color, the gestational or postnatal age is indicated in the right corner, and a $20 \mu \mathrm{m}$ scale bar is present in the lower left corner.

epithelium acquired a more diffuse cytosolic distribution of cytokeratin (Fig. 2E-H). Individual $\beta$-cells that were located outside the ductal epithelium also showed low level diffuse cytosolic staining for cytokeratin proteins, and $\beta$-cells clusters independent of ductal epithelium showed low or undetectable cytokeratin levels (Fig. 2I-L).

Similar immunostaining results were obtained for $\beta$-catenin (Fig. 3) and E-cadherin (Fig. 2Q-T). Insulin ${ }^{+}$ 



Figure $2 \beta$-Cells lose cytokeratin expression during islet formation. Representative photographs from sheep pancreatic sections immunostained for insulin (AMCA, blue), cytokeratin (Texas Red), and PDX1 (Cy2, green) illustrate cytokeratin expression in $\beta$-cells with respect to their location (A-P). The merge image is shown on the right, and the fetal age (dGA) is indicated in the bottom corner. The scale bars are presented on the insulin photograph and represent $10 \mu \mathrm{m}$. Solitary $\beta$-cells (white arrows) were observed adjacent to the epithelial lumen (A-D), within the epithelium but not adjacent to the lumen (E-H), and distinct from the epithelial layer (I-L). Small and large $\beta$-cell clusters were also independent of the epithelial layer and primarily cytokeratin- (I-P; yellow arrows). E-cadherin (AMCA), insulin (Texas Red), and NKX6.1 (Cy2) immunofluorescent staining is shown in Q-Tand the arrow head points to a bottle-shaped $\beta$-cell that has lower E-cadherin expression in its plasma membrane. In figures $D, H, L$ and T, the ' $a$ ' identifies the apical surface and ' $b$ ' the basolateral surface of the pancreatic epithelium.

cells within the ductal epithelium show distinct $\beta$-catenin framing of the plasmalemma, whereas cells adjacent to the ducts show a diffuse cytosolic $\beta$-catenin distribution, which disappears in $\beta$-cells that are located within $\beta$-cell clusters (Fig. 3A-C). Immunostaining with E-cadherin also declines in insulin ${ }^{+}$cells as they differentiate within the pancreatic epithelial layer (Fig. 2Q-T). These $\beta$-cells appear to be losing E-cadherin expression as they migrate to the basal surface of the epithelium and acquire a 'bottle-shaped' appearance that is reminiscent of a cell undergoing an EMT. Together, 


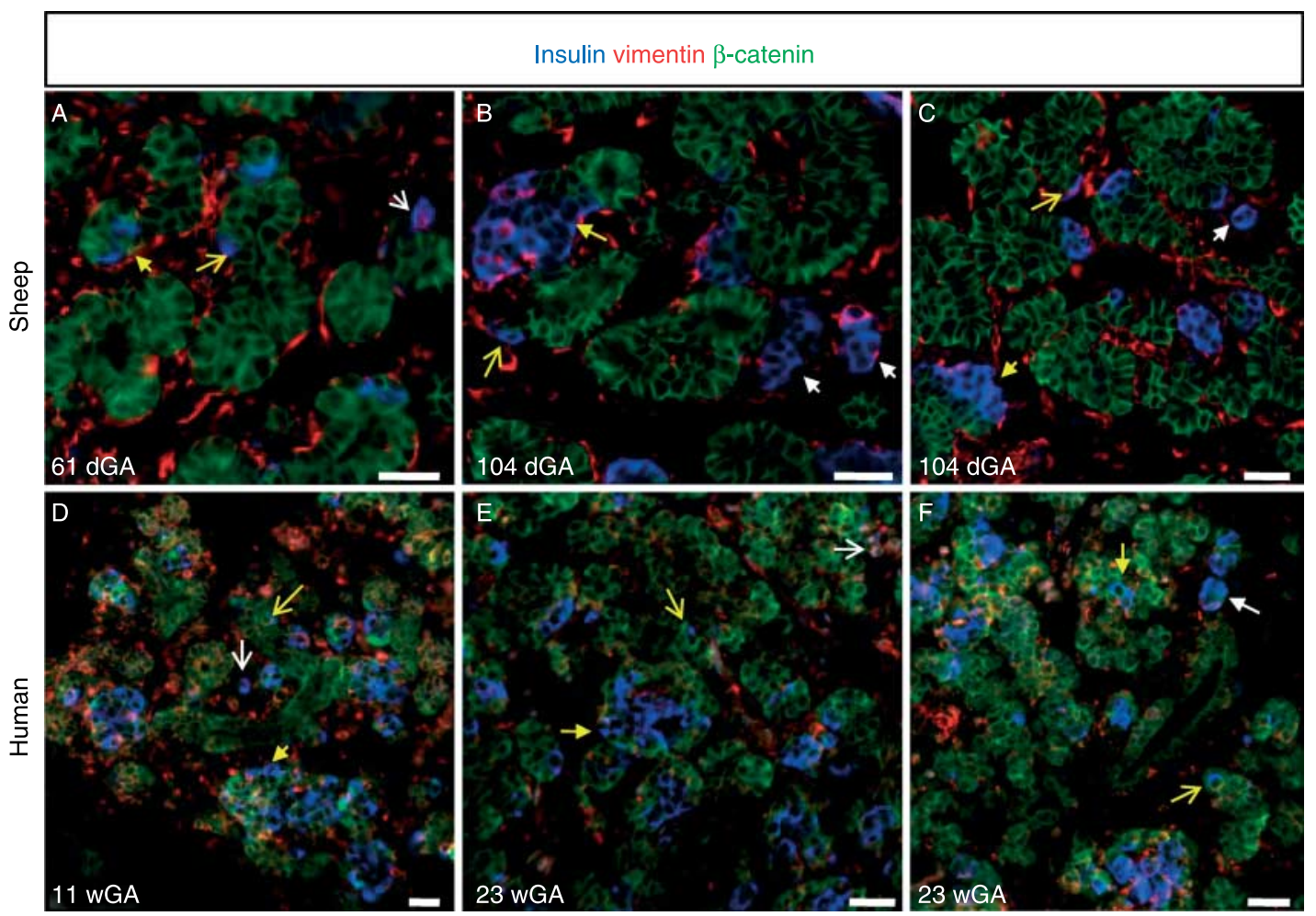

Figure 3 Two independent processes in sheep and human for $\beta$-cell coalescence into islets. Fetal pancreas tissues collected from sheep (top row) and human (bottom row) fetuses were immunostained for insulin (AMCA, blue), vimentin (Texas Red), and $\beta$-catenin (Cy2, green). The days (dGA) or weeks (wGA) of gestational age are indicated at the bottom of each image along with a scale bar that equals $25 \mu \mathrm{m}$. The white arrows identify solitary $\beta$-cells (open arrowhead) or $\beta$-cells clusters (closed arrowhead) located in the mesenchymal stroma independent from the ductal epithelium. The yellow arrows identify solitary $\beta$-cells (open arrowhead) or $\beta$-cells clusters (closed arrowhead) within the ductal epithelium.

these data show a transition in localization and expression levels of several proteins that are highly similar to those occurring during an EMT in other cell types (Thiery \& Sleeman 2006). Following cytodifferentiation (expression of insulin), $\beta$-cells within the ductal epithelium lose their epithelial phenotype and appear to exit the epithelium.

\section{$\beta$-Cells emerging from the ductal epithelium gain mesenchymal characteristics}

Vimentin, an intermediate filament protein that demarcates mesenchymal cells, was occasionally co-expressed with insulin in both the sheep and human pancreas (Fig. 3). While vimentin staining was rarely observed within insulin ${ }^{-}$ductal cells, some insulin ${ }^{+}$cells still associated with the ductal lumen were vimentin ${ }^{-}$, indicating differentiation takes place prior to developing a mesenchymal phenotype. Insulin $^{+}$cells within the epithelium but not in contact with the lumen, or located outside of the ductal epithelium, almost always showed vimentin staining (Fig. 4; Table 1). These findings suggest that vimentin expression becomes detectable as insulin ${ }^{+}$cells acquire a mesenchymal phenotype.

Because the temporal expression pattern of vimentin persisted in larger $\beta$-cell clusters (Table 1 ), we evaluated its expression in adult islets (Fig. 5). Strikingly, vimentin ${ }^{+}$ $\beta$-cells were found in adult sheep islets prompting further examination across different species. In human, vimentin ${ }^{+}$ $\beta$-cells were observed in the islets of Langerhans (Fig. 5). However, $\beta$-cells in rodents did not co-express insulin and vimentin, even though dual staining was observed during pancreas development in the mouse at embryonic day $15 \cdot 5$ (data not shown). These findings indicate that sheep and human islets have a small proportion of $\beta$-cells with a mesenchymal phenotype, which might provide a mechanism for continued islet expansion or remodeling in adulthood.

\section{SNAIL family members are expressed in the ductal epithelium}

To examine expression of SNAIL family members during sheep pancreas development, cDNAs coding for SNAIL1, SNAIL2, and SNAIL3 were cloned from fetal sheep pancreatic RNA. The sheep SNAIL1, SNAIL2, and SNAIL3 nucleotide sequences were 87,85 , and $71 \%$ identical to the human orthologs respectively (data not shown).

In situ hybridization analysis showed that mRNAs coding for SNAIL1, SNAIL2, or SNAIL3 were localized predominantly to ductal epithelial invaginations or budding 

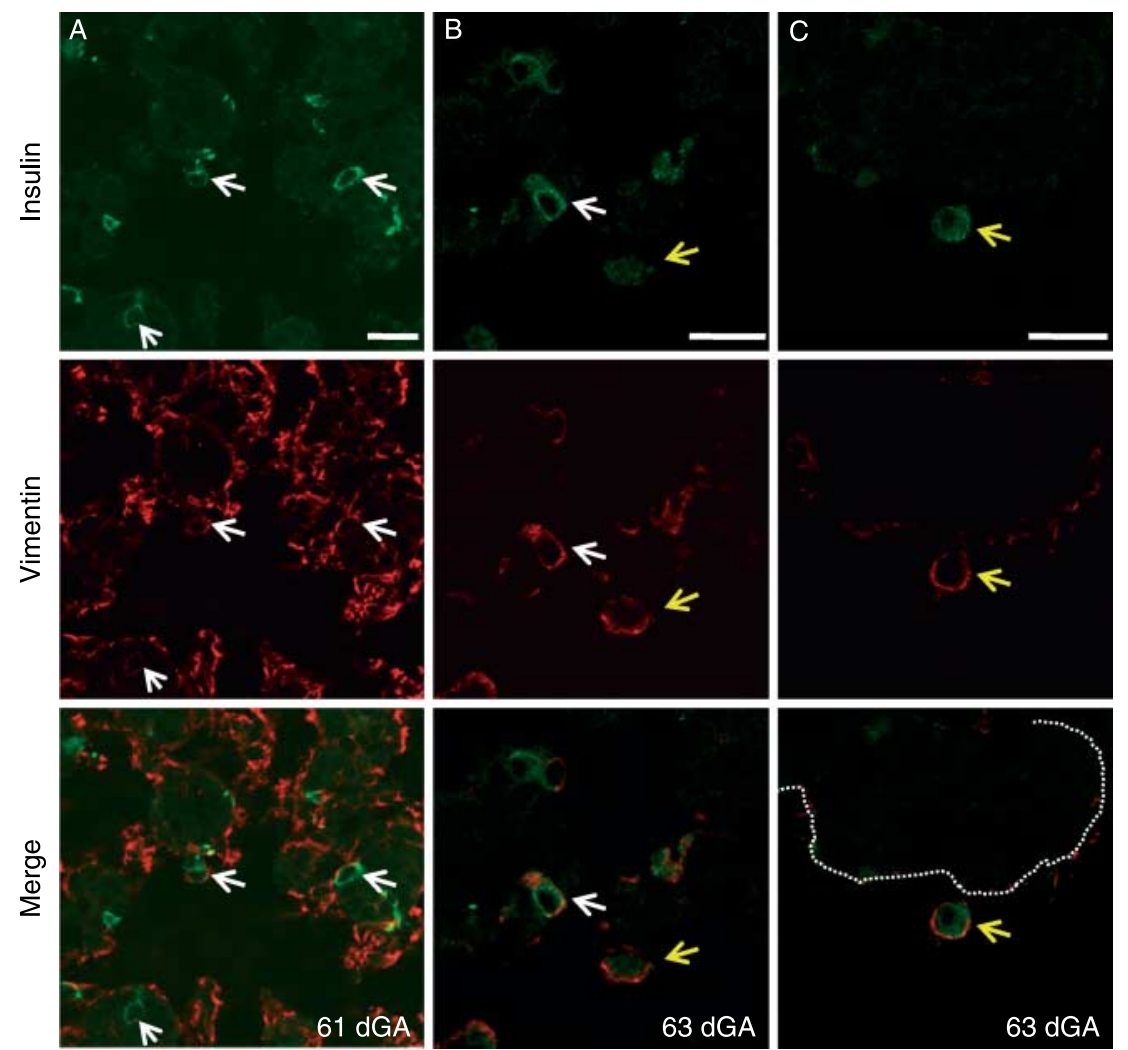

Figure 4 Vimentin expression in solitary $\beta$-cells. Fetal sheep pancreata were immunostained for vimentin (Cy3, red) and ovine insulin C-peptide (Cy2, green), and digital images were captured using confocal microscopy. Three representative images are shown $(A-C)$ for insulin, vimentin, and the merged image at 61 and 63 dGA. The arrows identify individual $\beta$-cells located within (white) or outside (yellow) of the epithelial layer, which is marked with a dashed line in C. The scale bars on the insulin stained images represent $20 \mu \mathrm{m}$.

structures (Fig. 6A-C), indicating these transcriptional repressors might play a role in branching morphogenesis within the pancreas as well as facilitating $\beta$-cell migration through an EMT. Sections stained for SNAIL1 mRNA or SNAIL2 mRNA were subsequently immunostained for insulin (Fig. 6A/D, B/E and F/G). A majority of the $\beta$-cells within clusters express SNAIL1 and -2 transcripts; however, the SNAIL1 and -2 expression was not exclusive because insulin $^{+}$SNAIL1 $^{-}$or insulin ${ }^{+}$SNAIL $^{-}$cells were also found in the pancreas (Fig. 6). Solitary $\beta$-cells not associated with the pancreatic ducts had low-level SNAIL1 and -2 staining (Fig. 6). $\beta$-Cell clusters that were associated with the ducts expressed SNAIL1 and -2 mRNA. Together, these findings place the SNAIL family members correctly in the pancreatic progenitor epithelium and newly formed $\beta$-cells.

Table 1 Proportion of vimentin ${ }^{+} \beta$-cells relative to the cluster size

\begin{tabular}{|c|c|c|c|c|c|}
\hline & \multicolumn{5}{|c|}{ Days gestational age } \\
\hline & $29(\%)$ & $33-40(\%)$ & $61-63(\%)$ & 95-109 (\%) & $129-142(\%)$ \\
\hline \multicolumn{6}{|c|}{ Cell number in cluster } \\
\hline 1 & $70 \pm 5$ & $62 \pm 7$ & $43 \pm 7$ & $27 \pm 5$ & $24 \pm 7$ \\
\hline $2-3$ & $56 \pm 5$ & $63 \pm 8$ & $42 \pm 5$ & $23 \pm 5$ & $21 \pm 5$ \\
\hline $4-10$ & $48 \pm 6$ & $51 \pm 8$ & $42 \pm 4$ & $24 \pm 8$ & $24 \pm 7$ \\
\hline $11-50$ & & $46 \pm 5$ & $46 \pm 5$ & $34 \pm 8$ & $21 \pm 3$ \\
\hline $50-100$ & & $29^{a}$ & & $64 \pm 17$ & $43 \pm 10$ \\
\hline$>100$ & & & & $55 \pm 13$ & $63 \pm 15$ \\
\hline
\end{tabular}

${ }^{\mathrm{a}}$ Only one cluster found in the age group. 

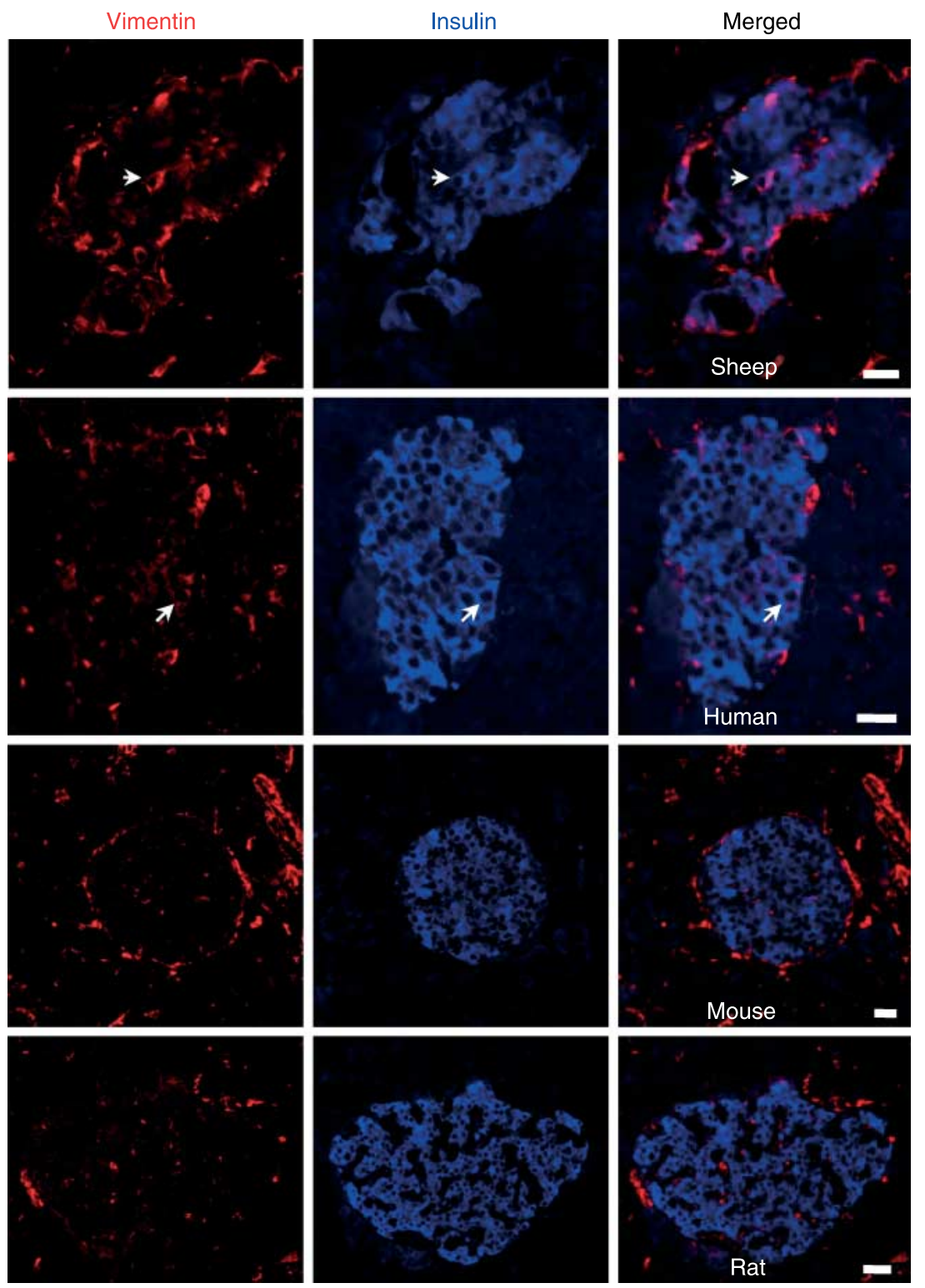

Figure 5 Vimentin $^{+} \beta$-cells in adult islets. Pancreas tissue from adult sheep, human, rat, and mouse were immunostained for insulin (AMCA, blue) and vimentin (Texas Red). A representative islet is shown for each species, which is labeled on the bottom of the merged image. White arrows identify a cell that is immunopositive for insulin and vimentin in the sheep and human, while dual staining was not observed in rodents ( $n \geq 5$ islets from at least five different mature individuals). In the merged images, the scale bars represent $20 \mu \mathrm{m}$.

\section{Discussion}

In this study, we show that the cascade of transcription factors mediating sheep endocrine cell specification parallels the genetic network defined in the mouse. Additionally, we distinguish two independent processes by which $\beta$-cells arise in the ductal epithelium and form islets of Langerhans. The first involves aggregates of ductal cells (the islet-forming unit) that begin to express insulin and then detach in mass from the duct, while the second involves individual insulin ${ }^{+}$cells that appear within the ductal epithelium and then exit the epithelium before migrating to form islets (Fig. 7). Through the use of a variety of cytoskeletal and transcription factor markers, we provide strong evidence that these latter cells exit the ductal epithelium via a classical EMT. Evidence to support this includes the localization of insulin ${ }^{+}$cells within 




Figure 6 Expression of the SNAIL family members in the sheep pancreas. On sheep pancreatic sections, in situ hybridizations were performed with antisense and sense (inserts) SNAIL1 (A), SNAIL2 (B and F), and SNAIL3 (C) cRNA. After capturing images for SNAIL1 and SNAIL2, the sections were subsequently immunostained for insulin to co-localize SNAIL1 (D) and SNAIL2 (E and G) to $\beta$-cells. The black filled arrows identify $\beta$-cells co-expressing SNAIL1 or SNAIL2. The open arrowheads identify SNAIL- insulin ${ }^{+}$cells. Scale bars in the antisense in situ hybridization pictures represent a $20 \mu \mathrm{m}$, and bars in the inserts (sense strand, negative controls) are $50 \mu \mathrm{m}$ long.

the ductal epithelium, at the periphery of the epithelium, and as individual cells within the pancreatic stroma, and corresponding transitions in expression and subcellular localization of proteins characteristic of epithelial and mesenchymal cells. $\beta$-Cells within the epithelium in contact with the lumen show E-cadherin, $\beta$-catenin, and cytokeratin expression closely associated with the plasma membrane.
$\beta$-Cells still within the epithelium that have lost contact with the lumen show more diffuse staining of these proteins, and some also exhibit the bottle shape that is characteristic of cells undergoing an EMT (Thiery \& Sleeman 2006). Individual $\beta$-cells within the stroma show diffuse or undetectable levels of E-cadherin, $\beta$-catenin and cytokeratin. Conversely, insulin ${ }^{+}$cells often express vimentin, with

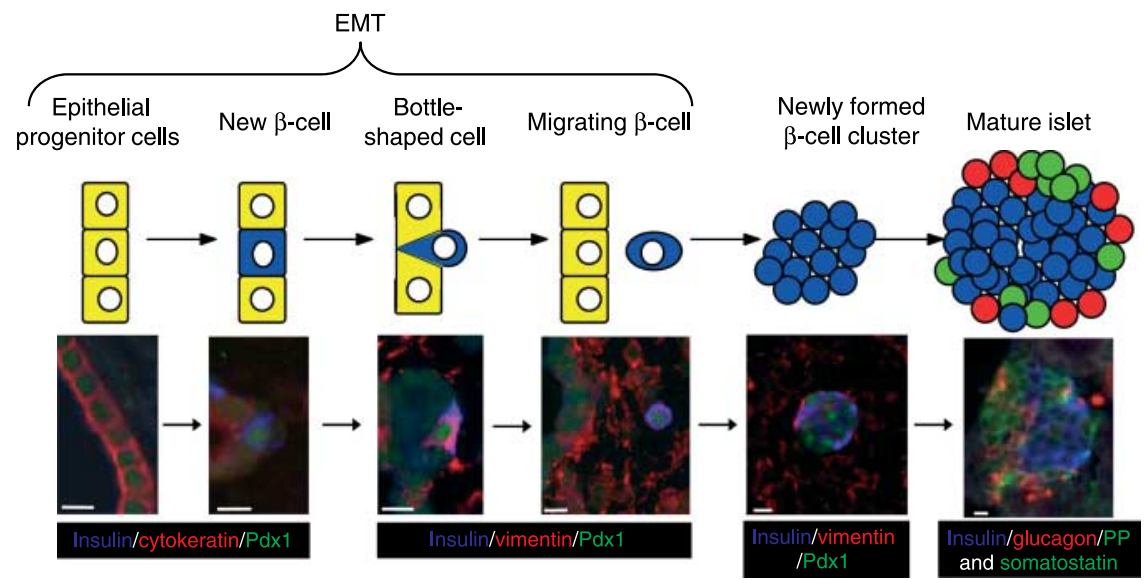

Figure 7 Single cell migration model of islet formation. A schematic with representative photographs is shown for the EMT process in sheep. In the model, $\beta$-cells (in blue) differentiate within the epithelial progenitor layer (yellow cells) and exit the epithelial layer. In the mature, islet cells in green and red represent other pancreatic endocrine cells. The triple immunofluorescent staining is labeled below each picture in the color representing its fluorescent staining and a scale bar representing $10 \mu \mathrm{m}$ is presented. 
proportions increasing in cells no longer in contact with the duct lumen or individual cells in the stroma. Finally, SNAIL1, SNAIL2, and SNAIL3 mRNA transcripts are expressed in the pancreatic progenitor epithelium, confirming that facilitators of an EMT are in the correct temporal and spatial location.

This study provides evidence for an EMT-mediated migration (or 'budding') process of islet formation (Fig. 7). However, $\beta$-cells appear to maintain the mesenchymal phenotype as they aggregate into clusters (Table 1). Moreover, in the islet-forming unit process we have also found that fetal $\beta$-cells co-express insulin and vimentin (Fig. 3), indicating that an EMT might be involved in islet remodeling. Therefore, an EMT appears to be an important developmental process for $\beta$-cell differentiation, irrespective of their mechanism for isletogenesis.

The single cell migration process was originally proposed to result from a parallel versus perpendicular cell division in which the axis of division is parallel to the apical-basal cell axis. Thus, one daughter cell is freed from the apical matrix, while the other daughter cell retains the epithelial junctional complexes and apical connections with its neighboring ductal cells (Pictet \& Rutter 1972). This mechanism of $\beta$-cell emergence was not disproved in this study, but $\beta$-cells were observed at the apical surface or found to have a bottle-shaped appearance (Fig. 2), similar to what is observed during an EMT in gastrulation (Shook \& Keller 2003). These bottleshaped $\beta$-cells undergo apical constriction, which reduces the surface area, the apical boundary length with adjacent cells, and tends to push the cytoplasm to the basal region of the cell, thereby causing a change in shape (Shook \& Keller 2003). These bottle-shaped $\beta$-cells have down-regulated cytokeratin expression and usually express vimentin, indicating that as $\beta$-cells leave the progenitor epithelium they acquire mesenchymal characteristics. The exact process by which $\beta$-cells bud off of the ductal epithelium remains to be completely defined, but both proposed mechanisms would require the loss of epithelial connections and migration out of the epithelial layer, a process resembling an EMT.

Vimentin expression in $\beta$-cells decreases during gestation in size-matched clusters (Table 1 ), yet as $\beta$-cells aggregate into larger clusters, some retain vimentin expression. Surprisingly, very large $\beta$-cell clusters $(>50$ cells), which are usually present in later stages of gestation (95-142 dGA), have a very high proportion of vimentin ${ }^{+} \beta$-cells (40-63\%), which may indicate a mesenchymal phenotype, is required for spatial remodeling within a forming islet. Islet remodeling and maturation occurs for 2-3 weeks after birth in the mouse pancreas (Habener et al. 2005) and for 6 months after birth in the human pancreas (Kassem et al. 2000). Similarly, islet remodeling was observed during the first 10 days in the lamb (Titlbach et al. 1985). In this study, we found vimentin ${ }^{+}$ $\beta$-cells in adult sheep and human islets, indicating that even mature islets might continue to remodel, which may require a mesenchymal phenotype. In contrast, adult rodent $\beta$-cells did not co-express vimentin. These findings demonstrate a striking variation between mammals that is not fully understood. Together, our data support that an EMT takes place during pancreas development in all species examined demonstrating that it is a conserved developmental process across vertebrate phylogeny, but this phenotype is not necessarily required in adult rodents.

SNAIL mRNA expression is localized to the pancreatic progenitor epithelium and also to $\beta$-cells within the epithelial layer (Fig. 6), illustrating they are expressed at the correct temporal and spatial location. $\beta$-Cells expressing SNAIL mRNA were located within the ductal epithelium and may be characterized as pre-migratory $\beta$-cells (e.g. $\beta$-cells preparing to leave the ductal epithelium). $\beta$-Cells located outside of the ductal epithelium that were SNAIL1 ${ }^{-}$or SNAIL2 ${ }^{-}$appear to be migratory $\beta$-cells. These migratory $\beta$-cells expressed vimentin; thus indicating the EMT has already taken place, which might reflect the downregulation of SNAIL1 (Peiro et al. 2006). Together, these data suggest a transient process for SNAIL1 and -2 proteins that allow $\beta$-cells to acquire a mesenchymal phenotype to migrate and then expression is lost until they coalesce into an islet (Komatsu et al. 1995).

SNAIL proteins have been found in all EMT processes studied (Nieto 2002), and their expression is regulated by growth factors (DeCraene et al. 2005), which also can influence subcellular localization and protein degradataion (Schlessinger \& Hall 2004, Zhou et al. 2004, Bachelder et al. 2005, Yang et al. 2005, Yook et al. 2006). The molecular mechanism initiating an EMT in islet formation remains unsolved. A potential regulator in the developing pancreas is transforming growth factor $\beta$ (TGF $\beta$ or TGFB1), a member of the TGF $\beta$ superfamily, which can induce SNAIL1 and SNAIL2 in vivo and in vitro (DeCraene et al. 2005). In the pancreatic islet, TGF $\beta$ is of particular interest because induces $\beta$-cell migration in rat pancreatic islets (Battelino et al. 2000). TGF $\beta$ enhances matrix metalloproteinase-2, which is necessary for proper morphogenesis of the islets and inhibition of TGF $\beta$ activity represses islet morphogenesis (Battelino et al. 2000). TGF $\beta$ signaling can activate expression of SNAIL transcription factors and the EMT process and is a likely candidate to be the initiator of an EMT in the formation of islets. However, this direct link has not been made until now and remains to be fully tested.

Recent reports indicate that an EMT regulates primary human $\beta$-cell expansion. Two studies with cultured human pancreatic islet cells found that pancreatic $\beta$-cells can undergo EMT and trans- or dedifferentiate into fibroblast-like cells. Following expansion, these cells were induced to differentiate back into hormone expressing cells (Gershengorn et al. 2004, Ouziel-Yahalom et al. 2006). During the transition from islet cells to proliferating fibroblast-like cells, epithelial cell markers such as E-cadherin, claudins, and occludins as well as endocrine markers declined, and mesenchymal cell markers, including vimentin and SNAIL, increased (Gershengorn et al. 2004). 
Following the mesenchymal-epithelial transition, the cells were allowed to aggregate; however, the newly-formed isletlike clusters were unable to produce functional quantities of insulin (Gershengorn et al. 2004). A similar study reported that proliferating human islet-derived (PHID) cells were induced to dedifferentiate, expand, and redifferentiate with $\beta$-cellulin, an epidermal growth factor family member that is mitogenic for $\beta$-cells (Ouziel-Yahalom et al. 2006). During expansion, the cells continued to express $\beta$-cell markers, indicating that PHID cells originated from $\beta$-cells rather than from a rare population of stem/progenitor cells. Interestingly, our findings show that a cohort of vimentin ${ }^{+}$ $\beta$-cells exist in the adult human and sheep islets, identifying them as an expandable population.

Conversely, in adult mouse islets a genetic-based cell lineage-tracing experiment showed that $\beta$-cells do not undergo an EMT in culture and do not significantly contribute to the proliferating fibroblast-like cell population (Chase et al. 2007, Weinberg et al. 2007). These studies did not examine this process during development, and so an EMT process may be involved in mouse pancreas development (Rukstalis \& Habener 2007). The difference between human and mouse appears to reflect some species divergence (Bliss \& Sharp 1992, Gershengorn et al. 2004, Ouziel-Yahalom et al. 2006, Russ et al. 2008). We show that adult human and sheep islets contain a few vimentin ${ }^{+} \beta$-cells and that these cells retain junctional complexes. The maintenance of the mesenchymal phenotype might suggest that adult human and sheep $\beta$-cells are capable of remodeling, whereas adult rodent $\beta$-cells do not appear to use this mechanism, confirming the species differences found in the in vitro data.

In conclusion, we show that $\beta$-cells exit the epithelial layer after differentiating by undergoing an EMT, following the conserved pattern of regulatory transcription factors for pancreatic endocrine cell determination. As demonstrated in other developmental systems, this induction appears to involve SNAIL proteins that facilitate the EMT. The expression of multiple epithelial and mesenchymal markers in pre-endocrine and new endocrine cells support this process in vertebrate $\beta$-cell differentiation. The information provided connects a large body of literature on pancreatic $\beta$-cell development to an extensive literature on EMT and provides promising new insight to refine strategies for $\beta$-cell expansion in vitro for islet replacement therapy.

\section{Declaration of interest}

The authors declare that there is no conflict of interest that could be perceived as prejudicing the impartiality of the research reported.

\section{Funding}

This work was supported by grant KO1-DK067393 and RO1-DK084842 (S W L, Principal Investigator) from the National Institutes of Health.

\section{Acknowledgements}

We would like to thank Drs John C Hutton and Suparna Sarkar for providing human pancreas sections as well as valuable intellectual insight. We would also like to express our gratitude to Drs Lori Sussel, Jan Jensen, and Jan $\mathrm{N}$ Jensen for their technical assistance and scholarly discussions on this project. Histological core service for the confocal microscopy was provided by the Cellular Imaging Shared Service, Integrative Health Sciences Facility Core in the Southwest Environmental Health Sciences Center at the University of Arizona.

\section{References}

Bachelder RE, Yoon SO, Franci C, de Herreros AG \& Mercurio AM 2005 Glycogen synthase kinase-3 is an endogenous inhibitor of Snail transcription: implications for the epithelial-mesenchymal transition. Journal of Cell Biology 168 29-33.

Battelino T, Miralles F, Krzisnik C, Scharfmann R \& Czernichow P 2000 TGF- $\beta$ activates genes identified by differential mRNA display in pancreatic rudiments. Pflügers Archiv 439 R26-R28.

Bliss CR \& Sharp GW 1992 Glucose-induced insulin release in islets of young rats: time-dependent potentiation and effects of 2-bromostearate. American Journal of Physiology 263 E890-E896.

Bocian-Sobkowska J, Zabel M, Wozniak W \& Surdyk-Zasada J 1999 Polyhormonal aspect of the endocrine cells of the human fetal pancreas. Histochemistry and Cell Biology 112 147-153.

Bonner-Weir S, Taneja M, Weir GC, Tatarkiewicz K, Song KH, Sharma A \& O'Neil JJ 2000 In vitro cultivation of human islets from expanded ductal tissue. PNAS 97 7999-8004.

Bouwens L \& De BE 1996 Islet morphogenesis and stem cell markers in rat pancreas. Journal of Histochemistry and Cytochemistry 44 947-951.

Chase LG, Ulloa-Montoya F, Kidder BL \& Verfaillie CM 2007 Islet-derived fibroblast-like cells are not derived via epithelial-mesenchymal transition from Pdx-1 or insulin-positive cells. Diabetes 56 3-7.

Chiang MK \& Melton DA 2003 Single-cell transcript analysis of pancreas development. Developmental Cell 4 383-393.

Cole L, Anderson MJ, Leos RA, Jensen J \& Limesand SW 2007 Progression of endocrine cell formation in the sheep pancreas. Diabetes 67 th Scientific Session Abstract Book, 1683-P. Ref type: Abstract.

DeCraene B, van Roy F \& Berx G 2005 Unraveling signalling cascades for the Snail family of transcription factors. Cellular Signalling 17 535-547.

Gershengorn MC, Hardikar AA, Hardikar A, Wei C, Geras-Raaka E, Marcus-Samuels B \& Raaka BM 2004 Epithelial-to-mesenchymal transition generates proliferative human islet precursor cells. Science 306 2261-2264.

Gradwohl G, Dierich A, LeMeur M \& Guillemot F 2000 Neurogenin 3 is required for the development of the four endocrine cell lineages of the pancreas. PNAS 97 1607-1611.

Grapin-Botton A 2005 Ductal cells of the pancreas. International Journal of Biochemistry \& Cell Biology 37 504-510.

Habener JF, Kemp DM \& Thomas MK 2005 Minireview: transcriptional regulation in pancreatic development. Endocrinology 146 1025-1034.

Jensen J 2004 Gene regulatory factors in pancreatic development. Developmental Dynamics 229 176-200.

Jensen J, Heller RS, Funder-Nielsen T, Pedersen EE, Lindsell C, Weinmaster G, Madsen OD \& Serup P 2000 Independent development of pancreatic alpha- and beta- cells from neurogenin 3-expressing precursors: a role for the notch pathway in repression of premature differentiation. Diabetes 49 163-176.

Kang Y \& Massague J 2004 Epithelial-mesenchymal transitions: twist in development and metastasis. Cell 118 277-279.

Kassem SA, Ariel I, Thornton PS, Scheimberg I \& Glaser B 2000 Beta-cell proliferation and apoptosis in the developing normal human pancreas and in hyperinsulinism of infancy. Diabetes 49 1325-1333. 
Komatsu M, Schermerhorn T, Aizawa T \& Sharp GW 1995 Glucose stimulation of insulin release in the absence of extracellular $\mathrm{Ca}^{2+}$ and in the absence of any increase in intracellular $\mathrm{Ca}^{2+}$ in rat pancreatic islets. PNAS 92 10728-10732.

Limesand SW, Jensen J, Hutton JC \& Hay WW Jr 2005 Diminished $\beta$-cell replication contributes to reduced $\beta$-cell mass in fetal sheep with intrauterine growth restriction. American Journal of Physiology. Regulatory, Integrative and Comparative Physiology 288 R1297-R1305.

Limesand SW, Rozance PJ, Smith D \& Hay WW Jr 2007 Increased insulin sensitivity and maintenance of glucose utilization rates in fetal sheep with placental insufficiency and intrauterine growth restriction. American Journal of Physiology. Endocrinology and Metabolism 293 E1716-E1725.

Nieto MA 2002 The snail superfamily of zinc-finger transcription factors. Nature Reviews. Molecular Cell Biology 3 155-166.

Nir T \& Dor Y 2005 How to make pancreatic beta cells - prospects for cell therapy in diabetes. Current Opinion in Biotechnology 16 524-529.

Ouziel-Yahalom L, Zalzman M, Anker-Kitai L, Knoller S, Bar Y, Glandt M, Herold K \& Efrat S 2006 Expansion and redifferentiation of adult human pancreatic islet cells. Biochemical and Biophysical Research Communications 341 291-298.

Peiro S, Escriva M, Puig I, Barbera MJ, Dave N, Herranz N, Larriba MJ, Takkunen M, Franci C, Munoz A et al. 2006 Snail1 transcriptional repressor binds to its own promoter and controls its expression. Nucleic Acids Research 34 2077-2084.

Pictet R \& Rutter WJ 1972 Development of the embryonic endocrine pancreas. In Handbook of Physiology Section 7: Endocrinology, pp 25-66. Ed. SR Geiger. Washington DC: American Physiological Society.

Piper K, Brickwood S, Turnpenny LW, Cameron IT, Ball SG, Wilson DI \& Hanley NA 2004 Beta cell differentiation during early human pancreas development. Journal of Endocrinology 181 11-23.

Radisky DC 2005 Epithelial-mesenchymal transition. Journal of Cell Science 118 4325-4326.

Rukstalis JM \& Habener JF 2007 Snail2, a mediator of epithelialmesenchymal transitions, expressed in progenitor cells of the developing endocrine pancreas. Gene Expression Patterns 7 471-479.

Russ HA, Bar Y, Ravassard P \& Efrat S 2008 In vitro proliferation of cells derived from adult human beta-cells revealed by cell-lineage tracing. Diabetes 57 1575-1583.

Sander M, Sussel L, Conners J, Scheel D, Kalamaras J, Dela CF, Schwitzgebel V, Hayes-Jordan A \& German M 2000 Homeobox gene Nkx6.1 lies downstream of $\mathrm{Nkx} 2.2$ in the major pathway of $\beta$-cell formation in the pancreas. Development 127 5533-5540.

Sarkar SA, Kobberup S, Wong R, Lopez AD, Quayum N, Still T, Kutchma A, Jensen JN, Gianani R, Beattie GM et al. 2008 Global gene expression profiling and histochemical analysis of the developing human fetal pancreas. Diabetologia 51 285-297.

Schlessinger K \& Hall A 2004 GSK-3beta sets Snail's pace. Nature Cell Biology 6 913-915.
Seeberger KL, Eshpeter A, Rajotte RV \& Korbutt GS 2009 Epithelial cells within the human pancreas do not coexpress mesenchymal antigens: epithelial-mesenchymal transition is an artifact of cell culture. Laboratory Investigation 89 110-121.

Shapiro AM, Lakey JR, Ryan EA, Korbutt GS, Toth E, Warnock GL, Kneteman NM \& Rajotte RV 2000 Islet transplantation in seven patients with type 1 diabetes mellitus using a glucocorticoid-free immunosuppressive regimen. New England Journal of Medicine 343 230-238.

Shook D \& Keller R 2003 Mechanisms, mechanics and function of epithelialmesenchymal transitions in early development. Mechanisms of Development 120 1351-1383.

Slack JM 1995 Developmental biology of the pancreas. Development 121 1569-1580.

Sussel L, Kalamaras J, Hartigan-O'Connor DJ, Meneses JJ, Pedersen RA, Rubenstein JL \& German MS 1998 Mice lacking the homeodomain transcription factor $\mathrm{Nkx} 2.2$ have diabetes due to arrested differentiation of pancreatic beta cells. Development 125 2213-2221.

Thiery JP \& Sleeman JP 2006 Complex networks orchestrate epithelialmesenchymal transitions. Nature Reviews. Molecular Cell Biology 7 131-142.

Titlbach M, Falt K \& Falkmer S 1985 Postnatal maturation of the islets of Langerhans in sheep. Light microscopic, immunohistochemical, morphometric, and ultrastructural investigations with particular reference to the transient appearance of argyrophil insulin immunoreactive cells. Diabetes Research 2 5-15.

Weinberg N, Ouziel-Yahalom L, Knoller S, Efrat S \& Dor Y 2007 Lineage tracing evidence for in vitro dedifferentiation but rare proliferation of mouse pancreatic $\beta$-cells. Diabetes 56 1299-1304.

Yang Z, Rayala S, Nguyen D, Vadlamudi RK, Chen S \& Kumar R 2005 Pak1 phosphorylation of snail, a master regulator of epithelial-to-mesenchyme transition, modulates snail's subcellular localization and functions. Cancer Research 65 3179-3184.

Yatoh S, Dodge R, Akashi T, Omer A, Sharma A, Weir GC \& Bonner-Weir S 2007 Differentiation of affinity-purified human pancreatic duct cells to $\beta$-cells. Diabetes 56 1802-1809.

Yook JI, Li XY, Ota I, Hu C, Kim HS, Kim NH, Cha SY, Ryu JK, Choi YJ, Kim J et al. 2006 A Wnt-Axin2-GSK3beta cascade regulates Snail1 activity in breast cancer cells. Nature Cell Biology 8 1398-1406.

Zhou BP, Deng J, Xia W, Xu J, Li YM, Gunduz M \& Hung MC 2004 Dual regulation of Snail by GSK-3beta-mediated phosphorylation in control of epithelial-mesenchymal transition. Nature Cell Biology 6 931-940.

\author{
Received in final form 1 June 2009 \\ Accepted 15 July 2009 \\ Made available online as an Accepted Preprint \\ 16 July 2009
}

